Portland State University

PDXScholar

\title{
Small Business Valuation: Deviations from Textbook Methods
}

\author{
Paul Hampshire \\ Portland State University
}

Follow this and additional works at: https://pdxscholar.library.pdx.edu/honorstheses

\section{Let us know how access to this document benefits you.}

\section{Recommended Citation}

Hampshire, Paul, "Small Business Valuation: Deviations from Textbook Methods" (2017). University Honors Theses. Paper 431.

https://doi.org/10.15760/honors.427

This Thesis is brought to you for free and open access. It has been accepted for inclusion in University Honors Theses by an authorized administrator of PDXScholar. Please contact us if we can make this document more accessible: pdxscholar@pdx.edu. 
Small Business Valuation: Deviations from Textbook Methods

by

Paul Hampshire

An undergraduate honors thesis submitted in partial fulfillment of the requirements for the degree of

Bachelor of Science

in

University Honors

and

Business Administration: Finance

Thesis Adviser

Lihong Qian, $\mathrm{PhD}$

Portland State University 


\section{TABLE OF CONTENTS}

Introduction

Why Value a Business?

2

Methods of Small Business Valuation

3

Determining the Discount Rate

7

Case Study and Application

10

Recommendations for Small Business Owners

11

Conclusions

11 


\section{INTRODUCTION}

Financial analysis within corporate finance has become a highly-developed field; however, as the name implies, these tools have been designed around use in large organizations, whose wealth of resources and human capital can be utilized in producing and analyzing financial data. As pointed out by Herbert Kierulff, a Seattle Pacific University business professor, in an article in BizEd, up to three-quarters of most university finance textbooks focus on valuation, yet these explanations almost exclusively focus on large, publicly-traded organizations (2015). This has also been the experience of this paper's author.

In practice, this can lead to massively overvaluing smaller, private firms: the same professor gives a real-world example of textbook methods providing a valuation of $\$ 45.6$ million for a private engineering services firm, whereas a professional evaluation team gave a figure of $\$ 7.4$ million. Valuation is an inexact science, bordering on art, with a plethora of different accepted methods-some variation in derived values is to be expected. However, a swing of 616 percent, as above, is hardly acceptable for a calculation that is ostensibly being utilized to make real-world decisions. Even among the professional ranks "[m]any analysts naively apply the same set of approaches, methods and procedures to the valuation of small businesses as they do to the valuation of substantial corporations" (MacLeod and Sloan, 2007).

This has implications for the economy as a whole. As the Small Business and Entrepreneurship council points out on their website, there were 5.73 million employer firms existing in the United States in 2012 and of this, fully 89.6 percent were firms that employed less than twenty people. After factoring in the additional 23 million businesses that do not have any employees, it's clear that the vast majority of businesses fall under the small business designation.

This paper's purpose is to review existing literature from an undergraduate perspective 
on the process of valuation and the differences in how valuation can be applied to large firms versus the adjustments needed to capture the value of very small businesses, defined for the purposes of this paper as those having less than 20 employees. Potential investors or buyers likely have more financial expertise and access to resources, so this information is also geared towards helping small business owners value their business for internal analytical purposes. To that end, a method for determining the discount rate for a small business is proposed.

\section{WHY VALUE A BUSINESS?}

The most obvious reason for conducting a business valuation is in order to buy or sell the business, which cannot be done without both parties agreeing on a reasonable price for the business. There are other advantages for an owner to have an understanding of the value of their business, including the ability to see what factors will affect their business's value (Kehrer, 2015). The use of spreadsheet software makes it very convenient to change inputs and see the resultant change in the valuation number. $A$ common tool in any financial analysis is to perform sensitivity testing. A highly useful variant of this idea is scenario analysis, such as setting up reasonable worst case, best case, and most likely scenarios or setting up an analysis of different strategic pathways which can then be compared with each other. This produces a range, which supports decision-making while also allowing the owner to account for uncertainty in their forecasts.

In the corporate finance and investment banking spheres, valuation is used for a variety of purposes. It can be used to price an entire entity in the case of mergers and acquisitions or to help facilitate ascertaining an appropriate stock price. It can also be used to value a project or division within the firm for the purposes of evaluating performance or capital budgeting analysis, which is used to provide guidance on whether a specific activity or project makes sense financially for the firm when resources are constrained. Some other reasons also include "business reorganizations, 
structuring shareholder agreements, minority shareholder actions and other shareholder disputes, employee share ownership plans and stock options, estate planning and income tax transactions." (Sim and Wilhelm, 2010)

\section{METHODS OF SMALL BUSINESS VALUATION}

Valuing a business entity can be done in a number of ways. Below follows a brief overview of these methods. This is by no means an exhaustive list, as many methods of valuation have been proposed, each with their own versions, modifications, and intricacies. Particular focus is given to the most popular models that would have the most relevancy to the small business owner, as well as discussing the challenges they are likely to encounter with proposed adjustments when available.

\section{Discounted Cash Flow}

Discounted cash flow analysis, DCF, is the textbook method used in valuation, to which an entire textbook could be devoted. In the interests of the author's sanity and the reader's time, a quick breakdown is presented of the various components.

The first critical element to understand is the time value of money. Basically this amounts to the idea that a dollar today is worth more than a dollar in the future, partly thanks to inflation, but more importantly due to the fact that a dollar you have today can be invested and provide a return tomorrow. On the other hand, if you do not receive that dollar until tomorrow, it cannot be invested and the return is foregone.

To calculate this effect, we essentially work backwards to derive the discount rate, which is equal to the rate of return that was expected from our investment. Because expected return should reflect the riskiness of an investment, using the discount rate essentially quantifies the riskiness of the cash flows. In corporate finance and investment analysis, the weighted average cost of capital (WACC) is used. The idea is that this value accounts for the expected return of all investors and creditors. For a small business 
that does not have investors, this is neither appropriate nor feasible to calculate the weighted average cost of capital. In most cases, small businesses are more risky than large organizations. The existing academic literature on valuation does not provide much guidance on how to determine the discount rate for small businesses. More discussion on determining this rate is provided in a later section.

The next critical element to understand is cash flow. There are several ways to get at what should work out to be the same number, but essentially the process involves taking earnings (generally EBIT or EBITDA) and adjusting them for non-cash items, taxes, investment in net working capital, and capital expenditures. If that sounds intimidating, the important thing to remember here is that we should be discounting the relevant cash flows. Free cash flow is designed to represent the money from operations that is available to investors and creditors. Most private companies aren't going to have investors and most small businesses have trouble securing loans of any notable amount, meaning that this type of cash flow would not be relevant.

An alternative and more relevant form of cash flow is the Seller's Discretionary Cash Flow (SDCF). This has the added bonus of being far less technical to calculate than FCF, while also simplifying the process of forecasting the cash flows. In order to derive SDCF, we simply take the net income before taxes and add back any non-cash items such as depreciation. In this case, we would not subtract any value for the owner's compensation, as this entire cash flow is meant to represent the owner's compensation. (Morris, 2015)

Once we have all this information, we then discount the cash flows using our discount rate to arrive at the net present value, which can be easily calculated within spreadsheet software. One of the issues for small business is that this does require financial statements and accurate accounting of the business. Considering the wealth of bookkeeping software in existence, such as QuickBooks, that can help business owners accomplish these tasks and the tremendous value in being able to analyze the 
business's financial performance, there is no reason for a small business not to have this.

\section{Asset-Based Valuation}

This might be the simplest and most straight-forward valuation method. Simply add up the value of all the business's tangible assets, such as land, equipment, and inventory. Commensurate with the valuation method's simplicity, there is also a lack of accuracy. A crucial missing piece then is the intangible assets, such as patents which can easily outweigh the tangible assets in value. We could certainly come up with a dollar amount for the intangible assets and add that back in, but then the question becomes how? For a small business owner who has put their blood, sweat, and tears into building up their business over a course of years, it can be hard to deal objectively with something so subjective. This method also completely fails to take into account the earning power of the business and any growth potential that exists.

For these reasons, this method is only ever appropriate when the business is defunct, although it can be also be used in certain lending situations to help determine the collateral value in the case of default leading to liquidation (Morris, 2015). An important note to make is that market values are always preferred over historical book values, although these at least work as an estimate when market data is not available. Frequently a business in distress will be sold in a condition where the buyer has more power, so these estimates might not be too far off after accounting for inflation.

\section{Capitalized Earnings Approach}

This approach is designed to account for the return on investment that a buyer expects from purchasing a small business. It's still a good idea to look at this method, since it can give the owner a sense of what a buyer might be expecting for the business, which will help with negotiations. The calculation for this is actually quite simple, we just take the average annual expected earnings of the business and divide it by the capitalization 
rate. Earnings can be adjusted to obtain various measures of cash flow, such as SDCF. The capitalization rate is then just the discount rate minus the growth rate of the business. This method can also be useful when an owner expects stable, consistent growth in their business, making it unnecessary to actually forecast out cash flow.

\section{Multiple Valuation Approach}

The great advantage of this model is that it accounts for the underlying economics of a transaction, chiefly supply and demand. The great disadvantage is that one must already have access to data on business entities that are as similar as possible to the business being evaluated. These are known as the peer group, and if this data is available, then it's possible to figure out a number to multiply the business's earnings by in order to arrive at a price. When done right, this can be an extremely effective valuation method.

Similar to DCF analysis, we want to adjust income for non-cash items and interest. It's also important to add back any expenses that don't represent true requirement's of the business, such as the owner's salary, a company car, or any travel expenses. An important note for small business owners is that, while we are attempting to go from an accounting accrual basis to a cash basis, it would be very unwise to add in any cash inflows that do not appear on the books. It's common for some cash to flow "under the table" in your average Mom n' Pop operation, but it needs to be left out of the valuation process. For one, anybody purchasing the business is not interested in information that isn't explicitly recorded and tracked-it's also unethical and could attract unwanted attention from the IRS (Siegil, 2011).

For small businesses in certain industries, it can be very effective to use a rule of thumb. Restaurants, for example, can always be found for sale and hence always have a fairly low multiple in the $1 x$ to $2 x$ range. Profitable manufacturing companies on the other hand are generally in high demand and can work out to have multiple at $4 x$ level or even higher (Siegil, 2011) 


\section{DETERMINING THE DISCOUNT RATE}

As noted earlier, finding an appropriate discount rate for a small business is the hardest part of applying discounted cash flow analysis to small businesses. Even for larger, privately-held businesses this can be tricky, as publicly-traded companies allow one to quickly determine their market value through, well, the market.

Utilizing the widely-used "pure-play" method for valuing closely-held firms, a method for adjusting the capital asset pricing model (CAPM) and arbitrage pricing theory (APT) to account for the undiversified nature of the average small business owner has been proposed (Hickman, Barnes \& Byrd, 1995). In keeping with the assumptions underlying corporate finance, the textbook versions of these quantitative models. In the case of this method, we still find difficulty in finding a comparable, publicly-traded company for a very small business that may operate in a niche industry or offer a limited product range in comparison to large companies within the same industry.

Still, because of the large emotional investment behind any small business owner who has most likely poured countless hours and sleepless nights into creating a successful enterprise, there is a huge need for an objective, quantitative method for estimating a discount rate. This is really the last hurdle for adapting financial analysis into a form that can benefit Main Street as much as it benefits Wall Street.

To that end, a simple model is proposed by this author to formulate a model for determining the discount rate based on the number of years in existence for the business. As noted by the Small Business Administration, failure rates of small businesses do not vary much by industry. Since very small businesses do not have a substantial amount of assets and are generally not very liquid, any sort of financial distress is highly likely to result in failure. Additionally, most small business owners have substantial portions of their wealth tied up in their business, making them undiversified investors who must consider total risk, rather than the non-diversifiable risk 
considered in the context of corporate finance. This makes overall business failure rates by number of years in existence a very tempting proxy as a concrete measure for the risk of a small business.

However, it is still necessary to find a way to convert those measures into a discount rate. Since the best way to determine a discount rate is through the market, this paper proposes looking at the extremes of riskiness and finding a middle ground through the use of proxies. The floor in this case would be the average cost of capital that large corporations use in internal decision-making, usually around 10-15\% (Ross, 1974).

Because tech startups generally require sizable capital investments and have high rates of failure, this paper proposes using them as a proxy for a ceiling to quantified risk. An added bonus is that the venture capital arena that has sprung up around U.S. tech startups means well-developed valuation methods are used for these types of smaller, private firms. The usual discount rate for these types of startups is $50-70 \%$, setting the ceiling for the purposes of this paper at an average of $60 \%$. Of note, it has been demonstrated that, after adjusting for the likelihood of success, the high discount rates used by venture capitalists become much more comparable to the corporate discount rates more familiar to standard textbook asset pricing models (Bhagat, 2013).

The Bureau of Labor Statistics publishes data for survival rates by number of years in existence for cohorts of newly established businesses dating from 1994-2015. Examining this data, it can be seen that $53.5 \%$ of new businesses survive to their fifth year, on average. We can compare this to research from Shikhar Ghosh of Harvard Business School stating that $75 \%$ of venture-capital backed startups fail to deliver back their invested capital over a span of five years (Gage, 2012). Because small businesses have low amounts of collateral assets and their owners generally depend on them for income, it's proposed that these are similar modes of failure, at least for estimation purposes. 
Research in the U.K. states that the annual failure rate nationally of corporations between 1980 and 1990 varied between $0.006 \%$ and $0.025 \%$ (Liu and Wilson, 2002). This is extraordinarily low when compared to the number of small businesses that fail each year. Similar new business failure rates are found between the U.S. and the U.K., therefore this rate is very likely to be comparable across most developed countries. The low rate of corporate failure-bordering on zero-lends credence to the proposition that common discount rates in corporations represent a floor for the riskiness of highlystable corporations. Looking at the variance between corporate failure and new venture failure, even for those businesses that have been existence for 20 years, the failure rate is still significantly higher, therefore the small business discount rate floor should represent the higher range of corporate discount rates at .

It's proposed, then, that a discount rate for a small business should start at rate of $60 \%$ for a newly started venture and decline for every year in existence. Utilizing the percent change of the data, a rough estimate for the failure rate by year is obtained, starting at $20 \%$ within the first year and declining to roughly $4 \%$ by year twenty. Fitting an exponential equation to this data provides the equation:

$$
y=4.817885+15.2785^{\star} e^{\wedge}\left(-0.3271136^{*} x\right)
$$

Where $x$ is the years in existence of the business starting at 0 and $y$ is the percent that will fail in that year. Scaling this equation to represent the ceiling of 60 as the $y$ intercept and the floor of roughly 15 as the horizontal asymptote yields a curve represented by:

$$
y=14.38433+45.61564^{*} e^{\wedge}\left(-0.327114^{*} x\right)
$$

While a great deal of assumptions and inexact data go into determining these rates, most valuation is an art not a science. Therefore, these rates are a great starting point of internal estimation purposes for small business owners. Further work could be done to make this model a more refined and elegant quantitative method backed by more extensive data. For example, older historical data on failure rates could extend the model to apply to businesses much older than 20 years. 


\section{CASE STUDY AND APPLICATION}

This paper was written in conjunction with a capstone project through the departmental honors section of Portland State's School of Business Administration. As part of this project, the author and several other students in the capstone class have been working together as a consulting team to help address the business needs of a small, local business. Due to non-disclosure agreements, the identity of the client is obscured and no exact financial data is presented other than the derived valuation numbers. Because other members of the group were working on financial analysis of the client project independently of this paper's author, it presents an interesting opportunity to apply the ideas outlined in this paper to a real live small business being analyzed by undergraduate students using the textbook methods that were taught to them.

Several scenarios were analyzed as a form of sensitivity analysis; for simplicity's sake only the base case "business as usual" forecast is used. The original analysis and forecast provided a valuation of $\$ 149,376$. Free cash flow was used in keeping with textbook corporate valuation methods. Working back and using EBIT instead to adjust for one-time expenses, non-cash items, and owner's benefits (in this case, rent paid for the house where the owner lives and works) in keeping with SDCF procedures actually increases this valuation to $\$ 404,740$.

The business in question has been in existence for 23 years; using the earlier model this gives a discount rate of roughly $14.4 \%$, higher than the $10 \%$ that was used in the original analysis. Applying this discount rate brings the total valuation back down to $\$ 178,443$. It might not seem like much, but this still represents nearly a $20 \%$ increase, which could represent a substantial amount of money for a larger operation. Based on the structure of the business, its underlying financials, and the degree of adjustments needed in the analysis, these numbers could potentially vary by a much higher amount. 


\section{RECOMMENDATIONS FOR SMALL BUSINESS OWNERS}

As with many things in business, the best course of action may be to consult an expert. While many undergraduate and graduate finance programs fail to provide even a cursory look at the process of valuing small businesses, there are many accounting and finance professionals who are engaged in this on a day-to-day basis and have acquired the relevant practical knowledge as well as certifications such as the CVA, or Certified Valuation Analyst. Especially where legal and tax matters are concerned, it might be mandatory or at least strongly encouraged that the owner receive the input of a recognized valuation expert. Owners seeking to go this route can contact the Small Business Administration for assistance finding a qualified professional.

As noted earlier, though, there are many practical applications for a small business owner to know the value of his or her business. In many cases, they simply do not have the resources to consult an expert and have their valuation updated every time conditions change within their business or marketplace. As long as owners keep in mind that they are not experts, and even if they were, any final numbers derived are estimates based on a set of certain assumptions, then they can use these to further develop their business and guide decision-making.

In the end, there really is no one-size-fits-all approach. Different situations call for different measures. In the case of a small business that operates in a large, active industry or market space with a lot of data on competitors, the multiple valuation method can produce a fairly reliable estimate with a minimum of work and technical know-how. For a small business that has a great deal of forecasted growth potential, DCF analysis is best poised to accurately capture the value inherent in that growth.

\section{CONCLUSIONS}

There are several methods available for small business owners, each with their own limitations and applicability to various business situations. Many of the standard 
textbook tools require tweaks to adequately capture the relevant value of a small business. Ultimately, l'd like to point out that this is an important topic in finance that is not covered in typical undergraduate and graduate courses. While it is somewhat specialized knowledge that probably does not deserve a lengthy treatment or it's own course, it should at least be touched upon within the standard curriculum. Having more professionals out there with this knowledge can only benefit society and the economy.

A quantitative model for determining a small business's discount rate was also proposed. To be sure, this model is simplistic and has many flaws, as one might expect for a quantitative method proposed by an undergraduate working within a technical field. Future work should focus on determining exactly how much of the failure rate is actually due to distress or inadequate profits and how much of it represents a financially successful exit or one purely due to personal, non-financial reasons. The Bureau of Labor Statistics data also does not distinguish between the sizes of new establishments; while it is reasonable to assume that most new businesses would be small, it's worth investigating this further.

Models have also been proposed to determine the failure rates of businesses, and these could potentially be repurposed towards finding proxies for discount rates assuming a valid correlation exists between the estimated failure rates of proxies and the discount rates prevalent in the market. On a similar note, more advanced methods of statistical analysis should be brought to bear upon this model. Other forms of risk should also be accounted for in a more rigorous and extended model. The author hopes that, at the very least, more investigation is inspired into what is clearly an underaddressed topic in the realm of finance that could have tangible benefits for the economy. After applying the proposed adjustments to an actual valuation done by undergraduate students at Portland State, it's clear how much variation in numbers there are and how much more work needs to be done to produce viable methods. 


\section{REFERENCES}

Morris, Marshall A. "Valuing the 'Mom \& Pop' Shop.” American Journal of Family Law 28.4 (2015): 169-170. Print.

Ross, Marc. "Capital Budgeting Practices of Twelve Large Manufacturers.” Financial Management (1972) 15.4 (1986): 15-22. Print.

Gage, Deborah. “The Venture Capital Secret: 3 Out of 4 Start-Ups Fail.” Wall Street Journal (Online); New York, N.Y. 20 Sept. 2012: n/a. Print.

Staff. “Adding Value.” BizEd 14.3 (2015): 64-65. Print.

MacLeod, Clyth, and Don Sloan. "Valuing SMEs -- Is It an Art or a Science?” Chartered Accountants Journal 86.1 (2007): 35-36. Print.

Bhagat, Sanjai. "Why do venture capitalists use such high discount rates?." The Journal of Risk Finance 15.1 (2014): 94-98. Web. 11 June 2017.

Investopedia. "Capitalization Of Earnings.” Investopedia. N.p., 28 Apr. 2008. Web. 29 May 2017.

Liu, Jia, and Nick Wilson. "Corporate Failure Rates and the Impact of the 1986 Insolvency Act: An Econometric Analysis." Managerial Finance 28.6 (2002): 61-71. Web. 11 June 2017.

Hickman, Kent A., Clarence Barnes, and John Byrd. "A Note on Estimating the Cost of Capital for the Undiversified Business Owner." Journal of Small Business Finance 4.2/3 (1995): 191-196.

Kehrer, Daniel. "Putting a Value on Your Business: Why and How." SCORE. SCORE Association, 15 Nov. 2016. Web. 3 June 2017.

Siegil, Peter. "Valuing a Small Business for Sale." SCORE. SCORE Association, 22 Apr. 2011. Web. 3 June 2017. 


\section{APPENDIX A - Survival Rates}

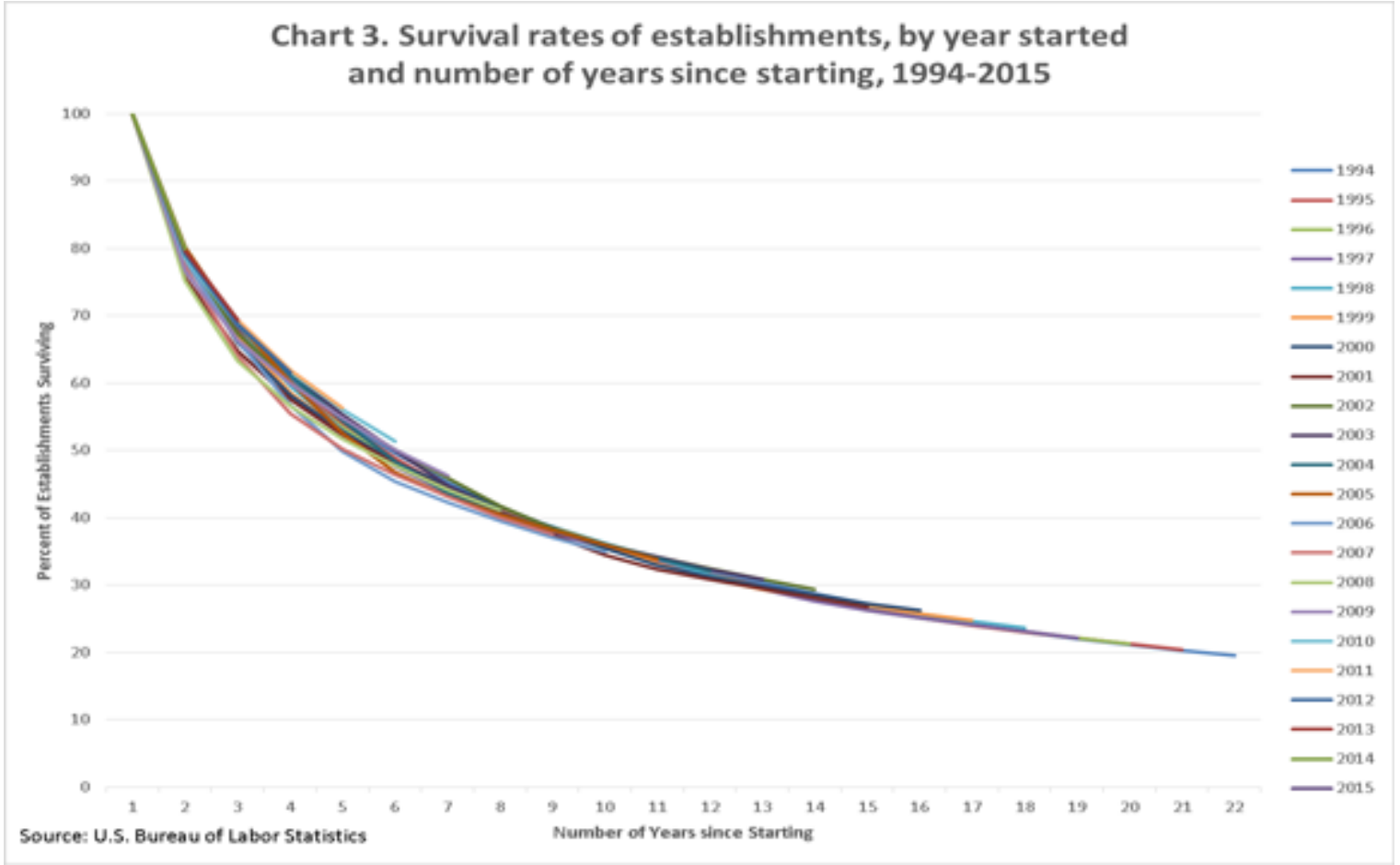

